\title{
"Goal-Driven" or "Data-Driven": An Ethnographic Study of MBO in a College in China
}

\author{
Deng Zijuan \\ Huaiyin Istitute Of Technology
}

\begin{abstract}
$M B O$ (management by objectives) is a popular management model in Western countries though its effectiveness was questioned. The study based on D college showed ideal "goal-driven" turned into "data-driven". Those including single X-theory, data orientation, lack of participation mechanism, dominant quantitative assessment and so on resulted in the variation of MBO. Rebuilding organizational trust, encouraging faculty to participate in management, improving organizational communication networks and regulating performance procedure are suggested for $D$ college to reconstruct the system of $M B O$.
\end{abstract}

Management by objectives (MBO) is result-directed and is also named management by results. As a response to New Managerialism, MBO is applied into higher education's management in many countries such as the United Kingdom, Australia, Denmark, Sweden, Switzerland and certain others (Kallio and Kallio, 2014). In corporations, if the employees took the objectives as fit, the appraisal as transparent and appropriate, the compensation as fair, MBO will do work. MBO as a management technology can't be fit to academy unless it was adjusted (Tsrpstra et. al., 1982). A study on universities in South-Center of China showed that $65.4 \%$ of them had already implemented or were going to implement MBO, most of which are supervised by the Ministry of Education (Dong, He \& Xiong, 2009). In recent years, MBO, as a management model, is supported increasingly by managers in higher education in China. However, does MBO really have a ready-made panacea?

\section{"Yes" or "No" to MBO}

\section{The Ins and Outs of $\mathrm{MBO}$}

MBO was not invented only by Drucker, though he laid the philosophical foundation for it. Drucker said that management was not only a science but also decision practices based on objectives (Greenwood, 1981). He emphasized that objectives were not given or obvious, and not everyone knows it. He objected to the concept that management was a process about goal-setting of plan-making. In his eyes, goal setting was so difficult that managers must take risks. Drucker paid attention to the result of management not the supervision activities themselves, and made a great contribution to help managers change their focus from hard work to productivity (Buskirk, 1976). MBO was put forward as a way to motivate rather than controlling the employees (Robbins, 2004). MBO is a process through which senior management and 
subordinate managers work together to define organizational goals, to define their responsibilities based on individuals' expected outcomes, and to use these indicators to guide the activities of their management and to evaluate the contributions made by each member (Odiorne, 1965).

There are four principles of MBO, i.e., goals, time, participation and motivation (Etzel and Ivancevich, 1974). Firstly, goals must be clear, planned and expected, concise and job-oriented which are concerned to not only quantitative performance but also staff development. Secondly, time provides the term for individual to achieve objectives of various levels, which can be six month, one year or even five years. Thirdly, participation refers to the fact that subordinates have to play important roles in setting goals in order to accept them fully. Fourthly, MBO means a motivation process that personal commitment and achievements will result in high internal job satisfaction.

At the first, the purpose of $\mathrm{MBO}$ is to use organizational goals to motivate managers and employees which turned to internal control, self-management and results from external control and process-oriented (Drucker, 1954). Nowadays, MBO means not only a management philosophy or a management model, but also an approach of organizational development and organizational change.

\section{The Strength of MBO}

McGregor pointed out that MBO was an effective way to solve the problem of inefficiency in traditional performance evaluation. According to him, MBO clearly defined the responsibilities of subordinates in performing goal-setting and evaluation and the focus of performance management changed from evaluation to analysis. This way works well because it stimulates employees' intrinsic motivation, and the managers become the coaches rather than supervisors (McGregor, 1987).

MBO had some advantages in better managing (Koontz, 1977). MBO may drive the plan effectively in which managers should plan for the expected results and take into account the resources and manpower required for plan implementation. $\mathrm{MBO}$ also helps to categorize and manage the organizational roles whose goals should fit the critical results and reflect from job responsibilities. MBO may stimulate employees' commitment through participating in goal-setting, planning one's own action, motivating sense of control and initiative. MBO is helpful to better control and instruct employees. That is to say managers know what to see and how to teach. MBO makes evaluation more operational than before. Evaluation based goals is objective because of being centered on what employees actually do rather than personal traits or work characteristics.

In addition, participation in management is important in MBO. The repeated consultations between the upper and the lower, comprehensive balance, all make the goals more mobilizing, motivating, and reachable (Odiorne 1984).

Goals themselves can motivate employees and turn the people's needs into motives, which will dominate the actions to reach their goals (Locke \& Latham, 1993). However, not every goal brings the positive effect. The effectiveness of MBO is related to goal specificity and difficulty. At the same time, commitment to goals, the importance of goals, self-efficacy, feedbacks and task complexity adjust the relationship between goals and performance.

\section{The Criticism to MBO}

Scholars questioned MBO even when it was very popular in the business field. Gratton (2000) pointed out that "the concept (MBO) is completely rooted in every organization, although the current MBO may be more driven by the data, this is not Drucker wanted to see".

According to Hamieson (1973), MBO may be problematic in the following ways: authoritative management, centralized decision-making and single-incentive assumptions, which are incompatible to MBO; MBO lacks senior management's support; MBO is difficult to adapt to organizational change, such as changes of organizational structure, authority and control; performance evaluation and interview are frustrated because of the lack of interpersonal skills; there are no dynamic job descriptions and results analysis; managers can't set goals appropriately and have no experiences in performance measurement 
which leads to too much emphasis on numbers ignoring the individuals' objectives; employees have no resources to realize their goals; there are no systemic quality control.

A famous American psychologist named Maslow said MBO was based on "responsible workers" which was a psychological proposition that "everyone is a mature person". He proved that in fact only a few people's mind could meet the "mature" standards, so it was wrong to think everyone as responsible which broke the basic human characteristics. MBO put forward by Drucker was an ideal type of management, where it should work very well if some well-developed people are eager to grow. These principles are useful, but only in the top of human development can be effective (Maslow, 1998).

The fatal flaw of MBO is not taking employees' motive into account. MBO overemphasized objectivity and quantitative indicators, while ignoring the role of human factors (Levinson, 1970). Corporations did not consider individual needs and aspirations when they set goals. Managers failed to realize that if the organization's goals were only mandatory choices that were not relevant to the dreams, aspirations, and personal ambitions of the mind, then, those goals would not be a strong incentive affecting individuals. Companies assumed that when employees joined the company, the company's mission and interests, individual needs and aspirations can be left aside, but ignored the fact that the staff work is to meet their psychological needs.

Deming, a quality management guru, referred to "goals" in the MBO as "quotas". "Quotas are a big obstacle to improve quality and boost productivity, and I have not seen any company establish a system to help employees improve their methods of work at the same time when it determines quotas." Deming even compared the MBO as "the traffic police every day to open a certain number of illegal tickets". Performance appraisal, whether it was called management control or any other names, including the management of objectives, was the only most devastating force in American management today " (Deming, 1988).

\section{RESEARCH METHODS AND PROCESSES}

\section{Field Introduction}

The author conducted field research from May 2014 to July 2016 in a local undergraduate institute (hereinafter referred to as D Institute) in East China. D is a provincial undergraduate institution located in the north of Jiangsu Province, which was founded as a specialist school in 1958. D became one of the colleges belonged to "National Excellent Engineer Education and Training Plan" in September 2011. In October of the same year, the State Council Academic Degrees Committee approved it to be one of the training units in name of "National Service Special Needs of the Master's Degree". A few science \& technology laboratories became national experimental demonstration centers. D has two campuses covering an area of more than 2,000 $\mathrm{mu}$ (about 570,000 square meters). It has 16 secondary colleges or teaching units, more than 60 undergraduate majors, one graduate major, with the number of all kinds of students nearly reaching to 20,000 .

There are 1068 full-time teachers in $\mathrm{D}$, among whom professors and associate professors account for $42.5 \%$, and those having doctorate and master's degree account for $89.7 \%$. There are 71 graduate mentors, 37 corporate advisors, and 78 part-time doctoral and master supervisors. There are four teachers receiving the "Special Subsidy of the State Council", three teachers selected as the members of Science \& Technology Innovation Team in Jiangsu Province, 17 teachers being trained by the " 333 Talent Project in Jiangsu Province", 58 teachers being trained as academic leaders and outstanding young teachers in the "Innovation Project in Jiangsu Province", 21 teachers being participants in high-level personnel training programs of the "Six-Category Top Talent Project in Jiangsu Province", 8 teachers listed to be municipal-level young experts who have made outstanding contributions, 246 teachers receiving training in the municipal "533 Talent Project". high-level talents such as members of the "Thousand Talents Program in China", "Outstanding Yong 
Personnel in China" or "Innovative and Entrepreneurial Talents in Jiangsu Province" have been employed flexibly by D.

\section{Research Process}

In this study, the background, related policies and practices of MBO in D were analyzed, and the problems existing in the $\mathrm{MBO}$ and the reasons behind them were discussed.

The leaders of D have kept a "university dream" since it was upgraded to an undergraduate institute. In May 2014, the new president took office and proposed MBO vigorously which marked the claims of "university condition" into the agenda. On the one hand, D learned the experiences of MBO from other institutes and established benchmarks for MBO through senior managers' visiting to each others' in Jiangsu Province. On the other hand, D set up MBO system according to the evaluation indicators of Chinese University Ranking ${ }^{3}$ by Wu Shulian. At the end of the same year, D initiated MBO in scientific research.

Take D's MBO in 2015 as an example. At the beginning of the year, the Scientific and Technical Department distributed the objectives mainly on paper and funding to each school (such as table 1), which would be measured and ranked by the end of the year. The objectives or indicators for each department were allocated in accordance with the number of senior titles or PhDs. In other words, the more professors or more $\mathrm{PhDs}$, the higher objectives or indicators are allocated. The research performance is measured through five indicators: (i) number of national scientific research projects; (ii) number of provincial and ministerial-level projects; (iii) the amount of the funding; (iv) the awarding numbers and the platform numbers of provincial and ministerial scientific and technological achievements; (v) the numbers of science \& technology innovation teams and the national invention patents.

TABLE 1

SCIENTIFIC RESEARCH ADVANCES REPORT IN D INSTITUTE

\begin{tabular}{|c|c|c|c|c|c|c|}
\hline \multirow[b]{2}{*}{ Unit } & \multicolumn{4}{|c|}{ Project funding ( 10 thousand yuan ) } & \multirow[b]{2}{*}{$\begin{array}{l}\text { Numbers of } \\
\text { provincial or } \\
\text { ministerial } \\
\text { awards }\end{array}$} & \multirow[b]{2}{*}{$\begin{array}{l}\text { Number } \\
\text { s of city } \\
\text { hall } \\
\text { awards }\end{array}$} \\
\hline & $\begin{array}{l}\text { Annual } \\
\text { objective } \\
\text { s }\end{array}$ & $\begin{array}{l}\text { Zongxia } \\
\text { ng } \\
\text { projects }^{4}\end{array}$ & $\begin{array}{l}\text { Hengxia } \\
\text { ng } \\
\text { projects }^{5}\end{array}$ & $\begin{array}{l}\text { Degree } \\
\text { of } \\
\text { completi } \\
\text { on } \\
\end{array}$ & & \\
\hline 1 & 452 & & 77.25 & $17 \%$ & & \\
\hline 2 & 248 & & 54.7 & $22 \%$ & & \\
\hline 3 & 320 & & 30.2 & $9 \%$ & & \\
\hline 4 & 204 & & 14.53 & $7 \%$ & & \\
\hline 5 & 634 & 235 & 81.35 & $50 \%$ & & \\
\hline 6 & 296 & 1 & 65 & $22 \%$ & & \\
\hline 7 & 281 & 8.6 & 9 & $6 \%$ & & \\
\hline 8 & 165 & & 6.55 & $4 \%$ & & \\
\hline 9 & 68 & 11.5 & & $2 \%$ & & \\
\hline 10 & 54 & 6 & 15.32 & $39 \%$ & & \\
\hline 11 & 171 & 1 & 2.8 & $2 \%$ & & \\
\hline 12 & 106 & 3.5 & 10 & $13 \%$ & & \\
\hline 13 & 53 & 4 & 13.9 & $34 \%$ & & \\
\hline Total & 3052 & 270.6 & 380.6 & $21 \%$ & & \\
\hline
\end{tabular}


Note: The data were counted at the end of June 2015 except annual objectives. Unit 1-7 are departments of science, technology, mathematic and engineering. Unit 8-13 are departments of humanities and social science. Three schools formed at the end of 2015 are not listed.

The MBO in science \& technology management are supported by performance appraisal standards and the rules of rewards and punishments. The evaluation criteria are as follows: completing (i) besides any one of (ii)-(v) indicates excellent level; completing any two of (ii)-(v) indicates good level; completing any one of (i)-(v) indicates qualified level; all five indicators are not met, which refers to unqualified level. The department will be rewarded or punished based on the performance appraisal: the excellent and the good are rewarded 150,000 yuan and 100,000 yuan respectively, of which 20\% is used to reward the key leaders; the excellent departments are awarded the titles of advanced units; the unqualified departments fail to receive advanced units automatically. The key leaders will be warned if the departments have not been qualified for two consecutive years.

The brief report on scientific work in 2015 showed that all departments had already completed the annual objectives. Since the Science \& Technology Department emphasized the funding numbers too much at the beginning, it made each department and school to focus on amounts of funds and numbers of fund in the end. The statistical data told us obviously that Hengxiang funds were more than Zongxiang funds, but lacking the high-level funding projects. As can be seen from the breakdown tables, the funding amounts dramatically increased to $1,000,000$ yuan in some humanity or social science departments in 2015. It is worth mentioning that so many Zongxiang projects were interdisciplinary researches even though participants had nothing to do with the research topics. For example, the political lecturer was in charge of financial management projects, and the history professor presided over marketing projects. A few humanity teachers applied for some computer software patents. Actually, the Zongxiang projects or patents were shabby as compared to Hengxiang projects. The truth is that there are many frauds in funding data, for example, political teacher's husband is good at computer science and the patent is titled with the wife's name. What's more, some faculty operated Hengxiang projects by signing fake industrial service contracts with business owners to earn scores.

Why did the project leaders research so many topics irrelevant to their professional fields? Why did the bosses spend so much money funding the Hengxiang projects? Nobody cared how Hengxiang projects worked in fact. The Science \& Technology Department of D was only responsible to audit contract texts, relative tables and funding accounts. In other words, if the project forms in line with the management rules, it would be established and recognized. Hengxiang projects originated to encourage intellectuals to use expertise to solve social real problems while they may be compensated for their services. In order to complete one's funding goals, Hengxiang projects were used by all means. Faculty members conspired with employers in Hengxiang projects by interest/relationship exchange. The employers didn't get any help in "Hengxiang Projects" but teachers in charge of such projects have been rewarded much more than others. All in all, this kind of $\mathrm{MBO}$ has deviated from the original intention of being goal-driven.

\section{Why Did "Goal-Driven" Turn to "Data-Driven"}

The president claimed that MBO is to improve organizational performance and attain the strategic objectives. However, the practices of the MBO eventually led to "data worship" as the by-products. Why did "goal-driven" turn to "data-driven"? The reasons may include economic hypothesis, quantified performance direction, top-down decision-making mechanism and a mere formal assessment system.

\section{A Single Hypothesis of Human Nature}

McGregor (1960) proposed X-theory and Y-theory, which categorized the human nature into two opposing kinds. X-theory advocated that people are lazy, self-centered and irresponsible. That is to say employees never care about organizational needs or goals, lack of rationality. The employees are difficult to assume self-discipline and impacted by others. Most people make a living by work to meet the basic 
physiological and security needs. Y-theory believed that people are hardworking, responsible, taking initiative and self-controlled. Most people take work for granted if the environment is conducive. Controlling or punishing is not the only effective way to achieve organizational goals. The employees are imaginative and creative, which have the potential to develop. X-model and Y-model were proposed in management field based on $\mathrm{x}$-theory and $\mathrm{y}$-theory respectively.

Most managers in D are supporters to $\mathrm{x}$-theory through their management practices. D spent lots of money to build a visual teaching center and each classroom was installed monitoring equipments in. Managers can control the classroom at any time. Teachers are exposed to "invisible eyes" with pressure. Of course, some teachers may be more serious in class teaching than before. But it doesn't work well for those who are always responsible for teaching. If faculty members can't win managers' trust, they will become upset and dissatisfied. At the same time, the Science \&Technology Department allocates research tasks to each department at the beginning of a year and measures the performance at the end of the year. Academic papers, Zongxiang projects, Hengxiang projects and so on are all corresponding to some research scores for everyone. Faculty's compensation is mostly dependent on the scores of their research performance. In this sense, D's management model belongs to X-model.

\section{Utilitarian Data-Oriented}

The publicity of annual research performance and research bonus strengthen the charm of numbers. Research projects, papers, monographs, teaching books, patents, awards and so on are all required to convert to scores following the scoring rules (such as table-2). For projects, more scores mean that the grantors' administration level is higher. For papers, more scores indicate the journals' level is higher. Whatever the contents are, the score depends on sponsors' or journals' status. When research performance is simplified to research scores, the value of research is not different from each other. For the research elites, they can distribute research scores to whoever they want to share with in D. With the sharing marks one can claim higher position and enjoy more allowances though he himself has no research performance. Scores can be shared with a strange dealer besides team members and co-authors. In other words, scores can be transacted for a price among strangers from different departments.

TABLE 2

\section{SCORING RULES IN D}

\begin{tabular}{|l|l|l|l|}
\hline Classification & Title & Score & Remarks \\
\hline $\begin{array}{llll}\text { Achievement } \\
\text { award }\end{array}$ & $\begin{array}{l}\text { Grand Prize of National Scientific } \\
\text { Research }\end{array}$ & 10,000 & $\begin{array}{l}\text { D must be the } \\
\text { first signature } \\
\text { Rnit. }\end{array}$ \\
\cline { 1 - 2 } Research project & $\begin{array}{l}\text { National Natural Science Foundation of } \\
\text { China }\end{array}$ & 1,000 & \multicolumn{1}{|l}{} \\
\cline { 1 - 3 } Patent & SCI/EI/CSSCI & $50-200 / 50 / 50$ & \\
\hline
\end{tabular}

Notes: Papers published in SCI Journals are scored differently with a range of 50-200.

After the implementation of the MBO, the Science \&Technology Department regularly publishes research briefing. Each briefing reports the progress of projects announcements, funds, patent applications and other research data or policies. The schedules of various announcements are all published in time. The briefing looks just like enterprises' sales charts and creates an invisible pressure on the managers. Then this pressure passes to the faculty through meetings, QQ, rewards/punishment/promotion rules, and other informal media. The remuneration of leaders is tied to the departments' research data. So the managers encourage teachers to contribute more in data through all kinds of communication channels. "Responsible for the objectives only" is a direct incentive for "data worship". 


\section{Lack of Participation Mechanism}

Goals become working motive mostly because employees participate in the goal setting. Managers must recognize the value and autonomy of employees so as to let them participate in management activities. Actually, participation itself means commitment to jobs. Setting goals jointly is the key link of the MBO. Middle-level managers' views were collected for the MBO, but the faculty members were all neglected. In the faculty's eyes, goals are only performance index. Take the revision of syllabus as an example, the Teaching Affairs Office (TAO) assigns the tasks to each school and then to department and lastly to each teacher. It seems like the processes of the MBO. However, the TAO made the rules while nobody checked the contents of syllabus but formats. The faculty can do nothing but be tossed by the TAO with the format rules.

This top-down way of task allocation may ensure the legality of goals to some extent but the faculty take goals as leaders' business or responsibility, but not their own job. Though individuals face the average task quota, they can't understand the meanings of the indicators. The faculty starts to strive to meet the quota until leaders link the rewards and penalties to indicators. The real research performance needs long-term investment and accumulation, as we know, but Hengxiang projects may be operated in short terms. "Data-driven" crisis was triggered when too much attention was paid to top design and there was no participation at the bottom.

\section{The Flood of Quantitative Assessment}

The research briefing from the Science \& Technology Department has become the work model to each department. At the end of a year, each department turns over the work summary to the personnel office. The summaries will be noticed on the Office Automation System (OA). From the beginning to the end, we can't find any new information because they are highly similar in format or content but data. There is an illusion that the bigger the numbers are, the better the performance is. All achievements or defects can be represented by numbers according to this logic. So for individuals or departments, performance appraisal means counting teaching hours, papers, projects, wining and so on. Someone feels embarrassed if he can't prove himself by numbers in public. Quantification becomes the synonymous with innovation unconsciously. Postgraduate entrance rate, students' attendance, fund amounts, paper numbers, teaching hours and so on are used to measure the performance of student counselors, administrators and faculty members, regardless of their family background, professional interest, course nature. This uniform data-driven performance appraisal results in the "data worship" behind.

Data-driven means a management system focusing on employees' performance through quantitative evaluation, especially counting the results or products. The incomes of employees depend on the scores they earn. As to the work processes and personal differences are all ignored by managers.

\section{DISCUSSION AND CONCLUSION}

Ideally, MBO will help D to become a university by meeting the ranking indicators. Specific, accepted and challenging goals can motivate employees to work hard. At the same time, performance evaluation and feedback in time are also important in MBO. However, D pursued performance data excessively while deviating from the expected orbit. The reality is that "goal-driven" management was replaced by "data-driven" management.

The MBO is not powerful as a management model until its prerequisites are satisfied. Staff participating in goal setting, standardized performance evaluation and reasonable incentives are all important for the MBO. While the MBO in D looks like management by objectives but it is seeking for data performance only. If $\mathrm{D}$ wants to motivate the employees by $\mathrm{MBO}$, it should take some measures. Firstly, it must rebuild organizational trust and encourage the employees to involve in management; secondly, it must improve the networks of organizational communication and strengthen employees' voices; thirdly, it should standardize performance management system and prevent data-driven actions. In 
the final analysis, the MBO is a systematic engineering which means faculty selection, training \& developing, performance appraisal, compensation and career planning are all coordinated. The MBO is neither "result-centered" nor "indicators-centered", but "people-oriented". The MBO is not only an ideal management philosophy but an organizational development model, which means some profound changes in organizational culture and human resource management system.

MBO in D represents managers' unilateral expectations, regardless of that faculty accepts the objectives or not. MBO needs managers and employees to cooperate with and trust each other. Anthropologists have already paid attention to organizational topics since $20^{\text {th }} 30$ s (Tian and Zhou, 2013). They used organizational ethnography to study cultures, rituals, and conflicts between employers and employees. The holistic and insiders' views from anthropology are helpful to make policies acceptable and build harmonious labor relationships in organizations. A different organizational culture should be reconstructed to meet the conditions of $\mathrm{MBO}$ through some new management rites and rituals in $\mathrm{D}$ (Trice and Beyer, 1984).

\section{ENDNOTES}

1. The "333 Talent Project" was initiated by the government of Jiangsu Province, which aimed at training 30 national-level scientists, engineering experts and theorists with internationally advanced research achievements, 300 provincial-level outstanding talents, and 3000 city-level leading talents.

2. The municipal "533 Talents Project " is a high-level academic and technical personnel training project in Huai'an City, which aims at selecting and training 50 academic and technical leaders with certain influence in China or in Jiangsu Province, 300 top-ranking young and middle-aged academic and technical talents, and 3000 leading talents in all fields in the city.

3. Wu Shulian and his team started to research on how to evaluate universities in China in 1991. They announced the first Chinese University Ranking in 1993 and then updated it annually.

4. Projects with signed research contracts with government departments or research institutions are called Zongxiang Projects.

5. Projects with signed technical contracts with other organizations for research and development are called Hengxiang Projects. 


\section{REFERENCES}

Buskirk, R. H. 1976. Handbook of Managerial Tactics. Boston: Cahners Books.

Deming, W.E. 1988. Out of the Crisis. Cambridge, Massachusetts: Cambridge University Press.

Dong Zefang, He Qing,\& Xiong Deming. 2009. "Research on the Implementation of Objectives Management in 75 Colleges and Universities." Higher Education Development and Evaluation, 25 (2): 15-21,120.

Drucker, P. 1954. The Practice of Management. NewYork: Harper Press, 128-129.

Etzel, M.J., \& Ivancevich, J. M. 1974. "Management by Objectives in Marketing: Philosophy, Process, and Problems." Journal of Marketing, 38(4): 47-55.

Gratton, L. 2000. Living Strategy: Putting People at the Heart of Corporate Purpose. New York: Prentice Hall.

Greenwood, R. 1981. "Management by Objectives: As Developed by Peter Drucker, Assisted by Harold Smiddy." Academy of Management Review, 6(2):225-230.

Hamieson, B. D. 1973. "Behavioral Problems with Management by Objectives." Academy of Management Journal, 16(3):496-506.

Kallio, K., \& Kallio, T. J. 2014. "Management-by-Results and Performance Measurement in Universities-Implications for Work Motivation.” Studies in Higher Education, 39(4):574-589.

Koontz, H. 1977. "Making MBO Effective." California Management Review, 20(1):5-13.

Levinson, H. H. 1970. “Management by Whose Objectives?” Harvard Business Review, 48 (7/8):125 $-134$.

Locke, E. A., \& Latham, G. P. 2002. "Building a Practically Useful Theory of Goal Setting and Task Motivation." American Psychologist, 57(9):705-717.

Maslow, A. H. 1998. "Toward a Psychology of Being (3rdEd.)." New York: Harper\& Row.

McGregor, D. M. 1960. The Human Side of Enterprise. New York: McGraw-Hill Education.

McGregor, D.M. 1987. “An Uneasy Look at Performance Appraisal.” Training and Development Journal, 41(6):66-72.

Odiorne, G. S. 1965. Management by Objectives: A System of Managerial Leadership. Marshfield, Massachusetts: Pitman Press.

Odiorne, G. S. 1984. The Human Side of Management: Management by Integration and Self-Control. Lexington, Massachusetts: Heath.

Stephen F. Robbins. 2004. Organizational Behavior (7th Edition). Beijing: Renmin University of China Press.

Terpstra, D. E., Philip D. Olson, P. D.,\& Lockeman, B. 1982. "The Effects of MBO on Levels of Performance and Satisfaction Among University Faculty." Group \& Organization Studies, 7 (3): 353-366.

Tian, G., \& Zhou, D. M. 2013. General Business Anthropology. Beijing: Chinese Finance and Economics Press.

Trice, H. M., \& Beyer, J. M. 1984 "Studying Organizational Cultures through Rites and Ceremonials." Academy of Management Review, 9(4):653-669. 